\title{
Instability Mechanism of Cavity-Bearing Formation under Tunnel Excavation Disturbance
}

\author{
Tao Liu $\mathbb{D}^{1},{ }^{1,2,3}$ Haotong Wang $\mathbb{D}^{1},{ }^{1}$ Xiuting Su, ${ }^{1}$ Kexian $\mathrm{Li}^{4}{ }^{4}$ Shiqun Liu, ${ }^{4}$ and Fengsong Guo ${ }^{1}$ \\ ${ }^{1}$ College of Environmental Science and Engineering, Ocean University of China, Qingdao, Shandong 266100, China \\ ${ }^{2}$ Key Laboratory of Shandong Provincial for Marine Environment and Geological Engineering, Ocean University of China, \\ Qingdao, Shandong 266100, China \\ ${ }^{3}$ Key Lab of Marine Environment and Ecology, Ministry of Education, Ocean University of China, Qingdao, \\ Shandong 266100, China \\ ${ }^{4}$ Qingdao Metro Line 1 Co., Ltd., Qingdao, Shandong 266000, China
}

Correspondence should be addressed to Tao Liu; ltmilan@ouc.edu.cn

Received 18 August 2019; Revised 10 February 2020; Accepted 12 February 2020; Published 11 March 2020

Academic Editor: Vassilis Sarhosis

Copyright (C) 2020 Tao Liu et al. This is an open access article distributed under the Creative Commons Attribution License, which permits unrestricted use, distribution, and reproduction in any medium, provided the original work is properly cited.

\begin{abstract}
Urban subway construction inevitably causes disturbances to the rock strata. It can even cause ground collapse accidents when construction encounters a bad geological body in the stratum. To verify the influence of cavities on surface settlement and the mechanism of formation instability, the instability mechanism of cavity-bearing strata under tunnel excavation disturbance was herein studied by tests using self-designed indoor models and numerical simulations. This study was based on the concrete project case of Qingdao Metro. Two groups of experiments (with and without cavities) were designed to simulate the four-step excavation by staged unloading of an airbag. The results show that the settlement value in the cavity state was about twice as much as that in the nonvoid state at the same stage. Besides the first step of excavation, in the numerical simulation, the settlement value of the same stage is about 1.3 times that of the model test. Simulating the deformation process of the surrounding rock in model tests shows that, in the excavation of the tunnel, the collapse surface of the tunnel arch roof will be connected with the sliding surface of the formation cavity. The cavity will gradually change from a regular circle to an ellipse or may even close, resulting in a sudden increase in land subsidence or even ground collapse. This indicates that disturbance during tunnel excavation would cause greater instability in a stratum when bad geological bodies, such as cavities, exist in the stratum.
\end{abstract}

\section{Introduction}

As an important part of the development of urban underground space, the subway has greatly reduced the congestion of ground traffic. However, due to the closedness of the underground space, comprehensive and accurate underground exploration information cannot be obtained, especially the existence of bad geological bodies, such as hollows and water sacs. The hazards caused to the construction process cannot be timely warned. Once an accident occurs, the harm is huge. At the same time, the stratum is inevitably disturbed during the construction of the subway, which further increases the possibility of stratum instability. According to previous studies [1-6], the main causes of stratum instability during subway construction are natural and man-made geological cavities, such as karst caves, soil caves, water sacs, and abandoned air-raid shelters. Severe stratum instability can even cause ground collapse, causing serious harm. In recent years, due to the large-scale construction of infrastructure in China, stratum instability has frequently appeared in some Chinese cities, which has seriously affected people's lives and property safety.

In view of the hazards of stratum cavities to the safety of subway tunnel construction, more and more scholars have studied this issue [7-11]. Abdulla and Goodings [12] studied the instability mechanism of the soil on the cavity structure by means of centrifugal model tests in the laboratory. Based on classical plastic boundary theory, Augarde et al. [1] 
carried out numerical simulations and evaluated the entire instability mechanism of spherical formation cavity, from the stable state to development into a ground crater. Ouyang [13] attributed ground collapse to groundwater seepage and studied the mechanism by which it affected the stability of formation cavity and caused formation instability and collapse. According to the research results, the ground collapse accident can be divided into four stages: groundwater level drop, formation cavity formation, cavity expansion, and subsidence formation. Hatzor et al. [14] proposed the following rock mechanics parameters to control the stability of shallow karst caves by studying the voids in karst areas: the thickness of the overburden layer, the span of the rock layer, and the shear strength of the structural surface. However, the current research mainly focuses on the instability of cavity-bearing strata in karst and goaf areas, and there is not much research on the development law of cavity-bearing stratum caused by urban subway construction. In general, the existing research cannot meet the urgent requirements for the prediction and prevention of urban cavity-bearing strata in real life.

The 3D model test cannot directly observe the instability of the stratum cavity during the construction of the subway, and the plane strain model test is acceptable. Therefore, a self-designed plane strain model test is used in this study. Using the Qingdao Metro as an example, this study evaluates a shallow buried subway tunnel in a cavity-containing stratum and uses plane strain model test and numerical simulation to investigate the mechanism of tunnel instability under tunnel excavation disturbance. The process of excavation, which takes place in four steps, is simulated by the uniform unloading of an airbag. The instability of the formation cavity during tunnel excavation is observed from a two-dimensional plane. The surface settlement data during this process is recorded and compared with results of numerical simulation. Based on this, the evolution process of ground damage under the influence of cavities and the law of surface settlement change are analyzed, and the instability mechanism of cavity-bearing formations under the disturbance of tunnel excavation is studied. This work provides a reference for the study of the disaster mechanism and disaster mitigation during construction of shallow buried tunnels in cavity-containing strata in cities.

\section{Engineering Background}

The nature of the formation of the Qingdao area is complex. According to the classification method of surrounding rocks in the Code for Geotechnical Engineering Investigation (GB 50021-2001) [15], nearly 19 sections of Qingdao Line 1 pass through Class V and VI soft surrounding rocks, while more than $70 \%$ of the main body of the tunnel between the Nanling Road Station to Zunyi Road Station section and Miaotou Station to Wenyang Road Station section passes through Class VI surrounding rock.

This study focuses on the tunnel in a section of the Qingdao Metro. The stability and deformation law of cavity formation with tunnel excavation in the weak surrounding Class VI rock is studied. The geological profile of the test section is shown in Figure 1.
The tunnel length is about $851.6 \mathrm{~m}$ and the distance between the left and right lines is between 13 and $15 \mathrm{~m}$. The buried depths of the roof and floor of the experimental interzone tunnel structure are $10.5-12 \mathrm{~m}$ and $17.5-18 \mathrm{~m}$, respectively. The cross section is almost circular; its height is $6 \mathrm{~m}$ and its width is $6.2 \mathrm{~m}$.

\section{Model Test}

3.1. Model Test System. In accordance with previous studies [16-18], in this work, the formation in the test interval was generalized to be a homogeneous and continuous Class VI weak surrounding rock, so as to carry out follow-up studies. Combined with the test conditions, the model test geometric similarity ratio $C_{\mathrm{L}}$ was determined to be $1 / 30$. According to the similarity theory, the similarity ratios of physical and mechanical parameters are as follows: natural density similarity ratio $C_{\rho}=1$, porosity ratio similarity ratio $C_{e}=1$, liquidity index similarity ratio $C_{I}=1$, cohesive force similarity ratio $C_{c}=1$, water content similarity ratio $C_{\omega}=1$, and compressibility similarity ratio $C_{\alpha}=1$. Based on the general principles of selecting similar materials and considering the difficulty of obtaining materials, the Yellow River Estuary silt was selected to simulate the Class VI surrounding rocks. Table 1 is a comparison table of physical and mechanical indexes of prototype materials and model materials. The physical and mechanical properties of the prototype materials are derived from the geotechnical survey report of the test section of the Qingdao Survey and Mapping Research Institute in April 2015, and the relevant physical and mechanical indicators of the model material (Yellow River Estuary silt) are derived from the research results of Ma [19].

This test employed the model test system of independent design to study the instability mechanism of the cavity formation under tunnel excavation disturbance. The main components of the system are the test model box system, the pressure relief system, and the displacement monitoring system. The model test system is shown in Figure 2.

The model test box is made of $8 \mathrm{~mm}$ thick steel plate, and its overall size is $570 \mathrm{~cm}$ length $\times 300 \mathrm{~cm}$ width $\times 800 \mathrm{~cm}$ height, as shown in Figure 3(a). The front of the model box is a retaining wall composed of 3 removable steel baffles. Among them, a hole of $\varphi 8 \mathrm{~mm}$ is left between the first and second baffles, which is penetrated by the airbag inflation tube embedded in the model box. After the soil was left to stand for 24 hours, each steel plate was drawn out, and then the acrylic plate was replaced for subsequent tests. The stratum cavity model is simulated by a cylindrical iron pipe made of $2 \mathrm{~mm}$ thick iron sheet, and the tunnel model is simulated by an inflatable airbag made of PVC material. The tunnel excavation process is simulated by the gradual unloading of airbag air pressure.

The typical section $(6 \mathrm{~m}$ high $\times 6.2 \mathrm{~m}$ wide $)$ of the Qingdao Metro tunnel was adopted in this experiment. In order to facilitate the related indoor model test, the cross section was assumed to be equivalent to a circle with a diameter of $6 \mathrm{~m}$. The buried depth of the roof of the interzone tunnel structure was $10.5-12 \mathrm{~m}$. In this work, $12 \mathrm{~m}$ was selected as the thickness of the overlying soil layer above 

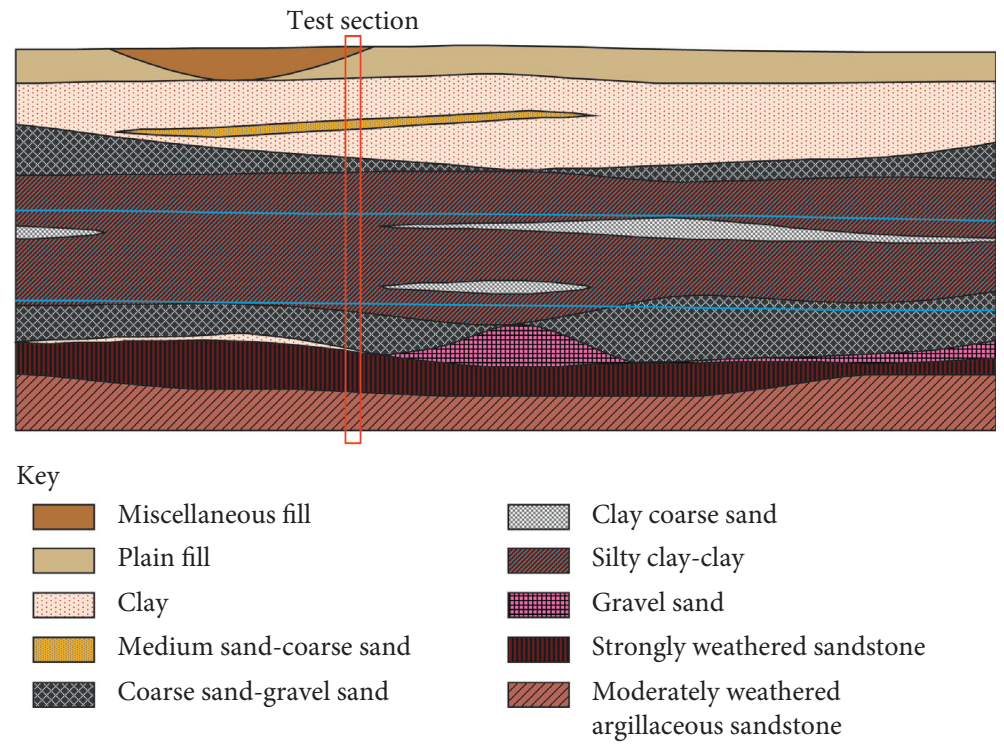

Figure 1: Test interval right line geological longitudinal section.

TABLe 1: Physical and mechanical indexes of the model material.

\begin{tabular}{lcccccc}
\hline Material name & $\begin{array}{c}\text { Natural density } \rho \\
\left(\mathrm{g} / \mathrm{cm}^{3}\right)\end{array}$ & $\begin{array}{c}\text { Porosity } \\
\text { ratio } e\end{array}$ & $\begin{array}{c}\text { Liquidity } \\
\text { factor } I_{L}\end{array}$ & $\begin{array}{c}\text { Cohesive force } c \\
(\mathrm{kPa})\end{array}$ & $\begin{array}{c}\text { Rate of water } \\
\text { content } \omega(\%)\end{array}$ & $\begin{array}{c}\text { Coefficient of compressibility } \\
\alpha\left(\mathrm{MPa}^{-1}\right)\end{array}$ \\
\hline $\begin{array}{l}\text { Prototype } \\
\text { material }\end{array}$ & 1.97 & 0.69 & 0.44 & 25.06 & 23.43 & 0.26 \\
$\begin{array}{l}\text { Model } \\
\text { material }\end{array}$ & $1.91 \sim 1.94$ & $0.74 \sim 0.83$ & $0.34 \sim 0.71$ & $13 \sim 27$ & $24.6 \sim 30.4$ & $0.162 \sim 0.243$ \\
\hline
\end{tabular}

the roof of the tunnel. According to the geometric similarity ratio, the diameter of the tunnel was determined to be $0.2 \mathrm{~m}$ $(6 \mathrm{~m} \times 1 / 30)$, and the thickness of the fill above the tunnel in the model box was $0.4 \mathrm{~m}(12 \mathrm{~m} \times 1 / 30)$. The diameter of the prototype cavity was $2.25 \mathrm{~m}$, so diameter of the model cavity was $7.5 \mathrm{~cm}(2.25 \mathrm{~m} \times 1 / 30)$. The design of the model is shown in Figure 3.

In this test, the support and excavation process of the tunnel is simulated by the stepped unloading pressure of the airbag. When filling the soil, the steel pipe is embedded in a specific position, and the steel pipe is taken out after the soil is left for 24 hours to form a simulated cavity. In order to reduce the adverse influence of the boundary effect on the indoor test, petroleum jelly was uniformly applied to the inner wall of the model box before filling.

3.2. Model Test Scheme. According to previous studies $[20,21]$, the influence of a cavity on the formation is greatest when the cavity is developed directly above the tunnel. Therefore, in this work, a circular-section cavity structure directly above the tunnel was selected. The experiment mainly investigated the instability mechanism with and without cavities in the stratum. Two sets of model tests were designed in this study, as shown in Table 2.

In each set of tests, the vertical displacement of the soil surface in the model box was monitored by fixing a laser displacement sensor on the suspended adjustable steel frame beam. The distance range of the displacement sensor is $200 \sim 1000 \mathrm{~mm}$, and the repeatability is $50 \mu \mathrm{m}$. For the convenience of reading, the reading accuracy is $1 \mathrm{~mm}$. In order to ensure the accuracy of the observed data, a scaling ruler is mounted on the top of the test model box near the acrylic baffle. The scaling ruler is made of PVC foam board; its size is $5 \mathrm{~mm}$ (thickness) $\times 100 \mathrm{~mm}$ (width) $\times 600 \mathrm{~mm}$ (length) (as shown in Figure 4). An elongated hole with a length of $50 \mathrm{~mm}$ and a width of $2-3 \mathrm{~mm}$ is cut out in advance on the scale as a ground displacement monitoring point so that the laser can pass through this hole for distance measurement. The direction of the scaling ruler is perpendicular to the direction of the tunnel excavation. The monitoring points were numbered from 1 to 15 . Among them, the spacing between monitoring points 6 and 10 was designed to be $2 \mathrm{~cm}$ to facilitate detailed monitoring of the vertical settlement at the key position directly above the tunnel. The spacing between points 1 and 6 and between 10 and 15 was designed to be $4 \mathrm{~cm}$. Figure 5 is the overall surface displacement monitoring point diagram of the model test, taking working condition 2 as an example.

The main steps of the model test are as follows: (1) Before filling the soil, smear petroleum jelly evenly on the inner walls of the test model box, iron baffle and acrylic baffle. (2) Inflate the tunnel model airbag with an initial air pressure of $0.08 \mathrm{MPa}$. (3) Fill the model box with soil, and place the tunnel and cavity model in the preset position. Let the soil rest for 24 hours after the filling is completed. (4) Take out 


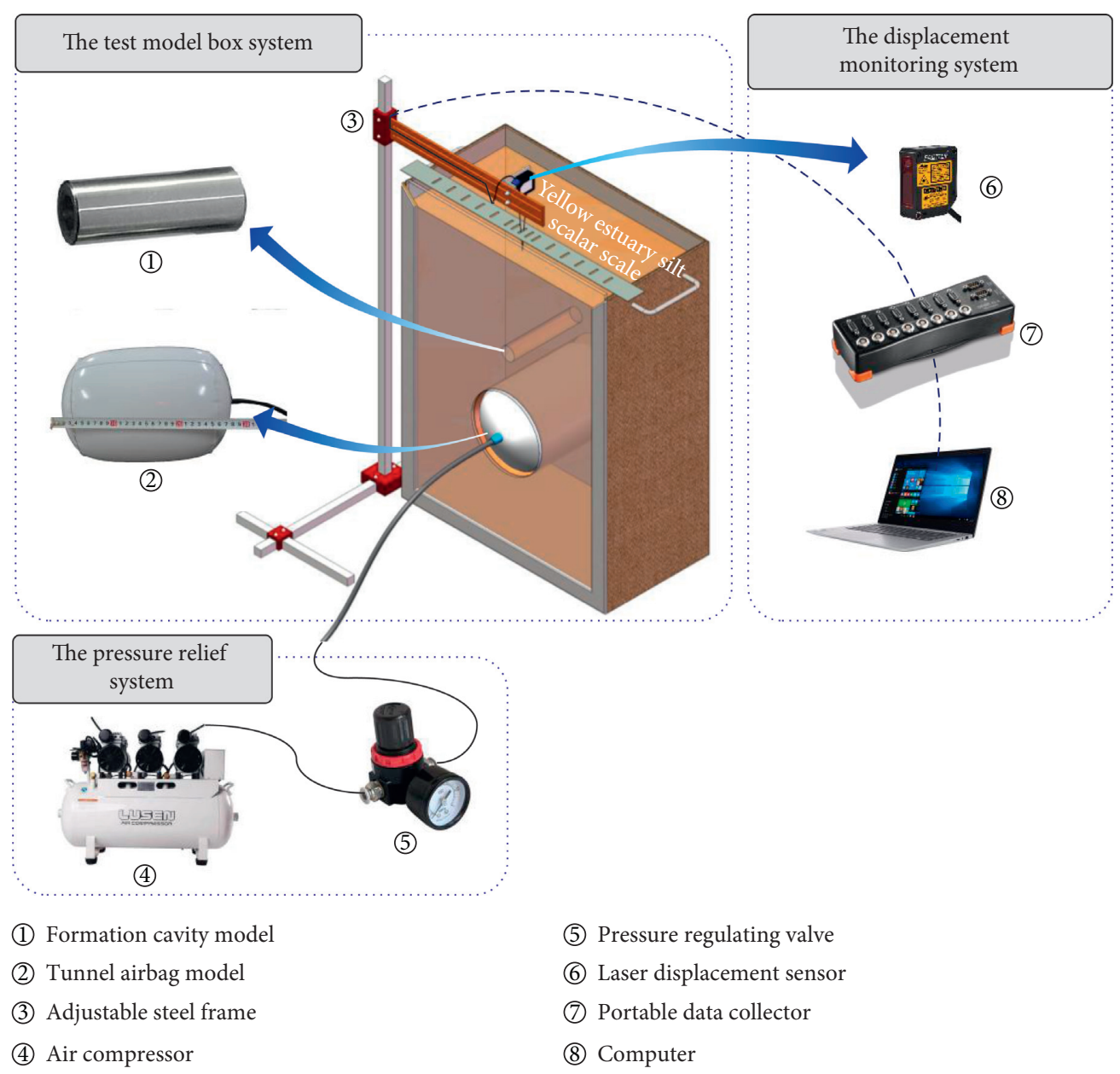

FIgURE 2: Indoor model test system diagram.

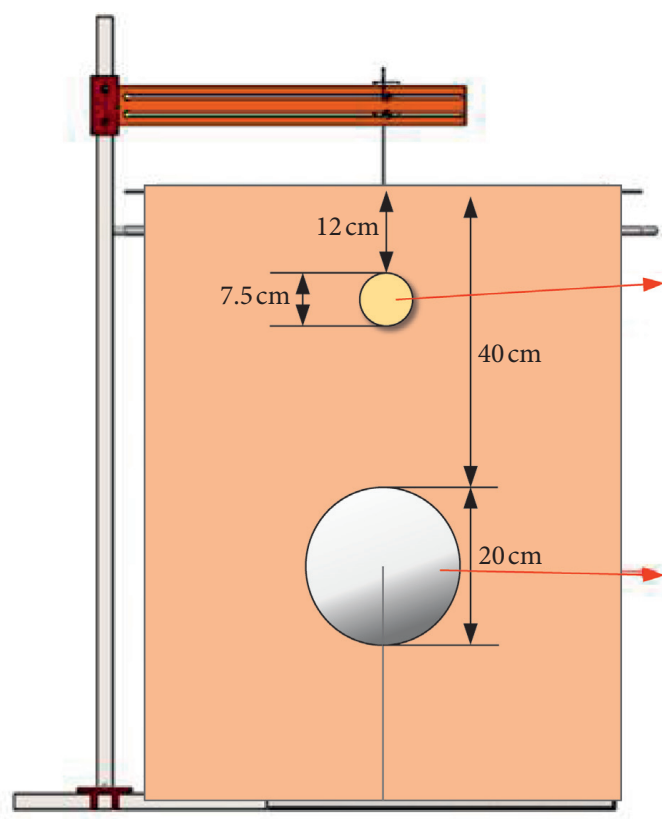

(a)
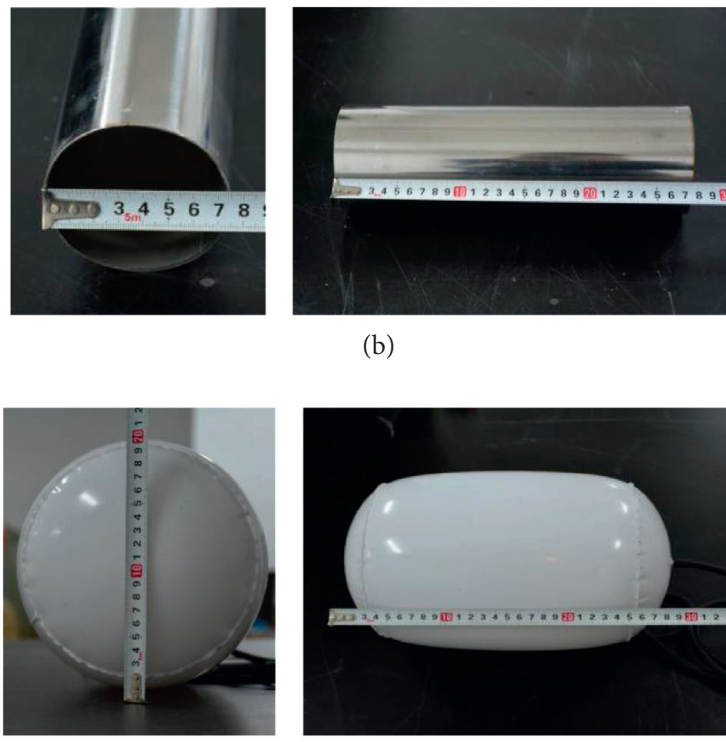

(c)

Figure 3: Model design. (a) Model design parameters. (b) Simulated cavity. (c) Simulated tunnel. 
TABLE 2: Model test plan design.

\begin{tabular}{lccccc}
\hline $\begin{array}{l}\text { Working } \\
\text { condition }\end{array}$ & Tunnel diameter $D(\mathrm{~cm})$ & Tunnel arch depth $H(\mathrm{~cm})$ & Cavity position & Cavity diameter $d(\mathrm{~cm})$ & Cavity depth $h(\mathrm{~cm})$ \\
\hline 1 (without cavity) & 20 & 40 & - & - & - \\
2 (with cavity) & 20 & 40 & Directly above & 7.5 & 12 \\
\hline
\end{tabular}

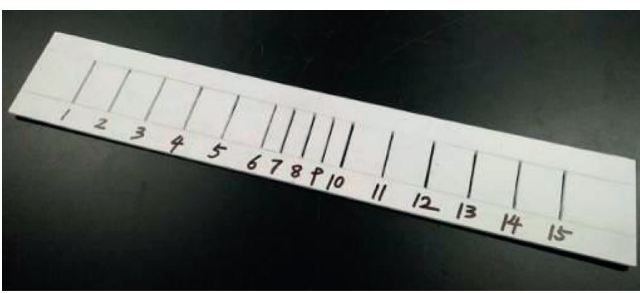

(a)

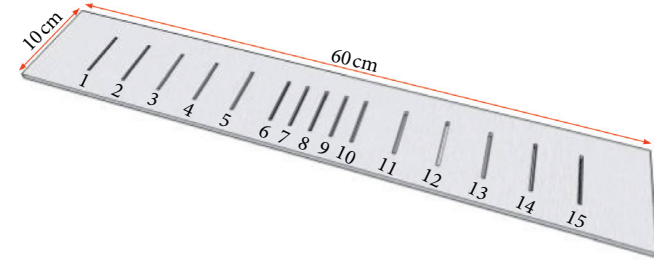

(b)

Figure 4: Scaling ruler. (a) Physical drawing. (b) Impression drawing.

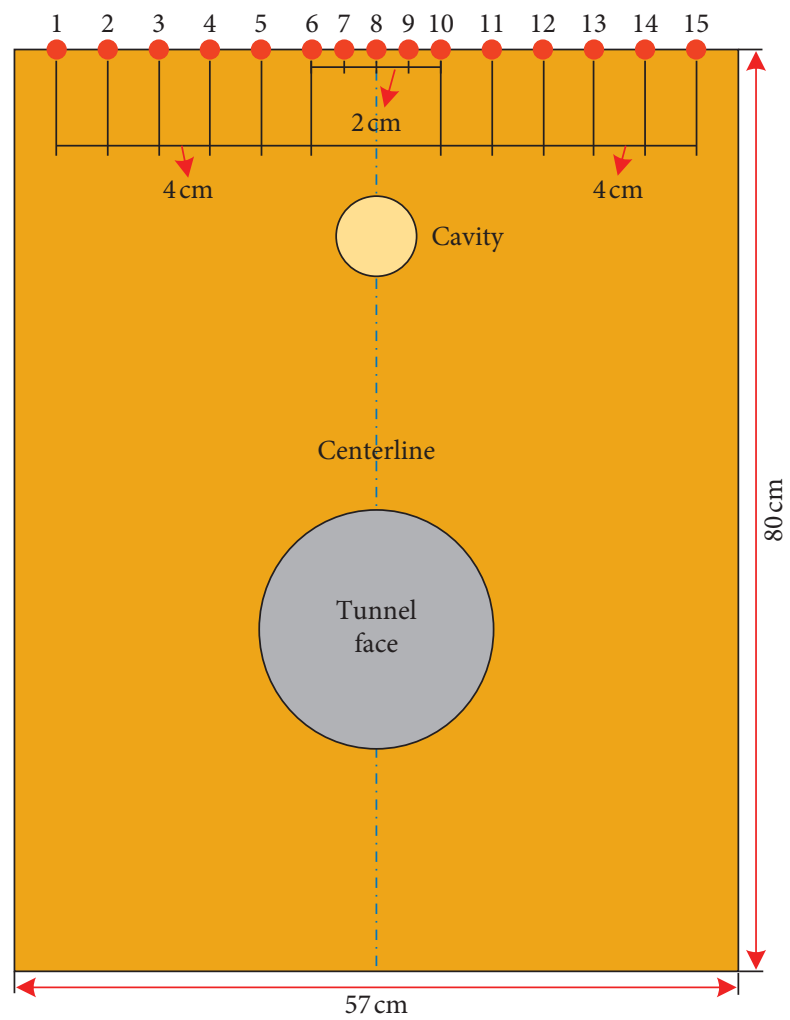

FIGURE 5: Ground displacement monitoring layout.

three iron baffles separately and replace them with acrylic baffles. When working condition 2 is carried out, the preburied steel pipe needs to be taken out to form a stratum hollow. (5) Install displacement sensors and scaling ruler. (6) The excavation is simulated by reducing the pressure in the tunnel airbag by adjusting the valve, and it is unloaded in four stages. The pressure of each unloading is controlled at about $0.02 \mathrm{MPa}$. After each unloading, it is required to stand for $1 \mathrm{~h}$ before the next unloading. Real-time monitoring and recording of vertical surface displacement data are required at each test stage.

\section{Numerical Simulation}

4.1. Building the Numerical Model. In order to make a better comparison with the model test, a four-step method based on the principle of the staged unloading of the model test airbag was selected to simulate the step-by-step excavation. The 4-step method is often used in the construction of surrounding rock tunnels in Class V or Class VI rock. In this work, the unsupported 4-step method under two different working conditions (with and without cavity) was used to numerically simulate the instability mechanism of cavitybearing strata under tunnel excavation disturbance. Figure 6 is a tunnel model excavated by the 4 -step method. Figures 7 and 8 are numerical models for tunnel excavation without and with cavity, respectively.

The constitutive relationship of the selected soil is simulated by the Mohr-Coulomb constitutive relationship in the MIDAS GTS NX software system. This constitutive relationship can well consider the special geological conditions in the soil. Its physical concept is clear, the calculation is accurate, and the parameters are few and easy to obtain. It can also fully consider the various engineering properties of the soil. Therefore, it is widely used in finite element analysis in geotechnical field.

After dividing the tunnel excavation models into two groups (without cavity and with cavity groups), the total number of solid models in working condition 1 was 12,941 , and the number of nodes was 8,269 ; the number of solid models in working condition 2 was 25,944, and the number of nodes was 15,634 . In addition, when the $3 \mathrm{D}$ solid model was meshed, the size of the whole unit was set to $1 \mathrm{~m}$. The tunnel entity and the stratum cavity were controlled in advance, and the dimensions of the two areas were set to $0.5 \mathrm{~m}$ and $0.2 \mathrm{~m}$, respectively.

4.2. Selection of Model Parameters. Corresponding to the model test, the numerical simulation was carried out in a single homogeneous formation (silty clay). Formation parameters for numerical simulation are derived from on-site 


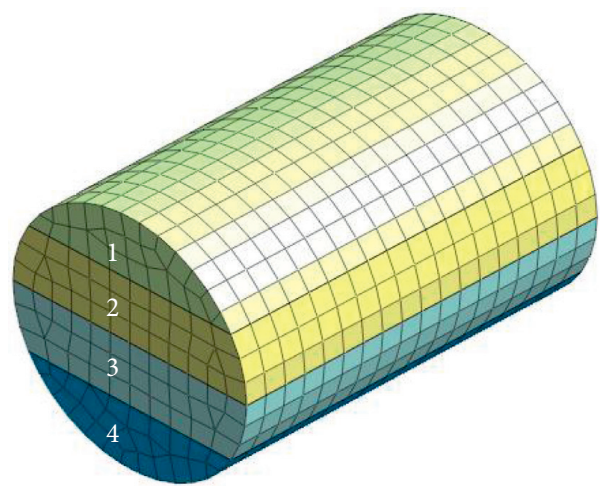

FIgURE 6: Tunnel model (4-step method).

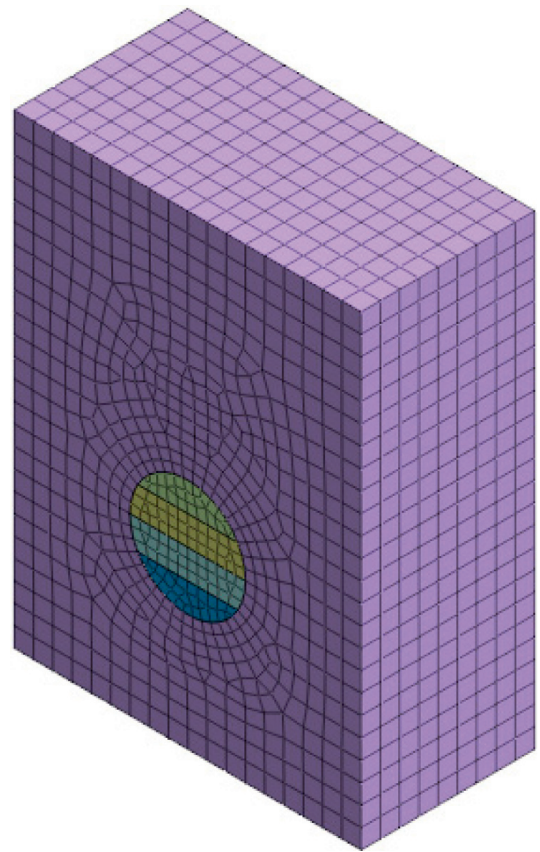

(a)

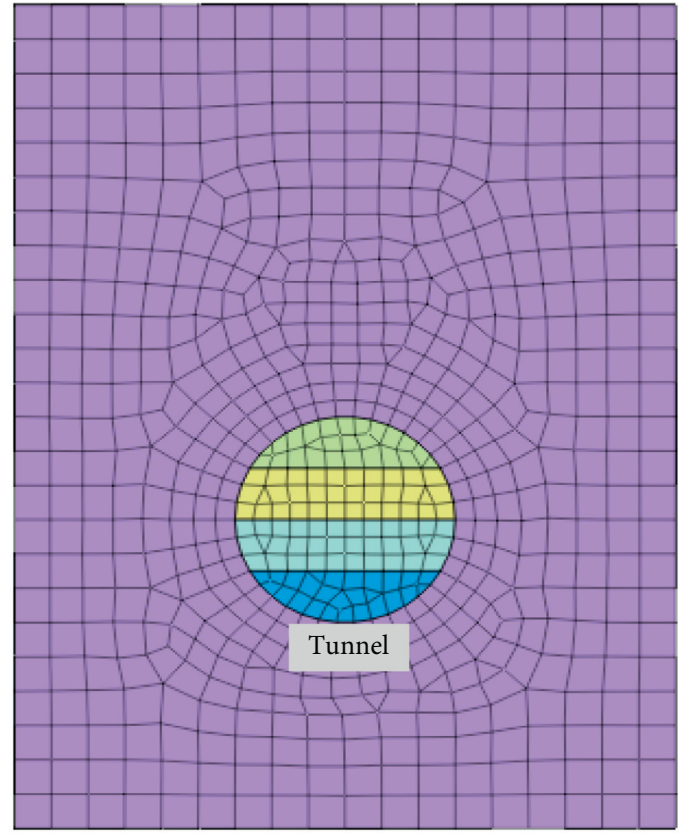

(b)

Figure 7: Tunnel excavation model without cavity. (a) Axonometric drawing. (b) Front elevation.

geotechnical survey report, as shown in Table 3. In addition, the actual size of the numerical modeling was 30 times that of the model test; i.e., the model dimensions were $18 \mathrm{~m}$ (length) $\times 9 \mathrm{~m}$ (width) $\times 24 \mathrm{~m}$ (height), the tunnel was a $6 \mathrm{~m}$ cylinder, the step height was $1.5 \mathrm{~m}$, and the longitudinal length was $9 \mathrm{~m}$ per step. The diameter of the formation cavity in working condition 2 was $2.25 \mathrm{~m}$, the longitudinal length was $9 \mathrm{~m}$ per step, and the overall buried depth was $3.6 \mathrm{~m}$.

\section{Results and Analysis}

5.1. Analysis of Model Test Results. Generally speaking, the surface settlement trough is similar to a normal distribution, which is in accordance with the formation loss theory. The three-dimensional surface settlement trough caused by tunnel excavation is shown in Figure 9.

Figures 10(a)-10(e) depict the evolution process of nocavity formation under tunnel excavation disturbance.
When the unloading pressure $P$ is $0.02 \mathrm{MPa}$ (Figure 10(b)), a slight arc-shaped sinkage occurs at the surface directly above tunnel. When $P$ is $0.04 \mathrm{MPa}$ (Figure 10(c)), the unloading airbag leaves an empty space in the upper half, and the tunnel vault generates multiple slits. When $P$ is $0.06 \mathrm{MPa}$ (Figure 10(d)), the original crack of the tunnel vault extends directly above and obliquely upward to form an irregular slump surface. The inner drop block of the tunnel increases; the vertical displacement of the surface is increased to form a temporary stable settlement groove. When $P$ is $0.08 \mathrm{MPa}$ (Figure 10(e)), surface settlement is maximum, and the cracks of the tunnel roof extend upward and finally form a stable arch collapse.

Figures 11(a)-11(e) depict the unstable evolution process of the cavity formation under tunnel excavation disturbance. When the unloading pressure $P$ is $0.02 \mathrm{MPa}$ (Figure 11(b)), a slight deformation occurs in the cavity. When $P$ is $0.04 \mathrm{MPa}$ (Figure $11(\mathrm{c})$ ), the airbag leaves an 


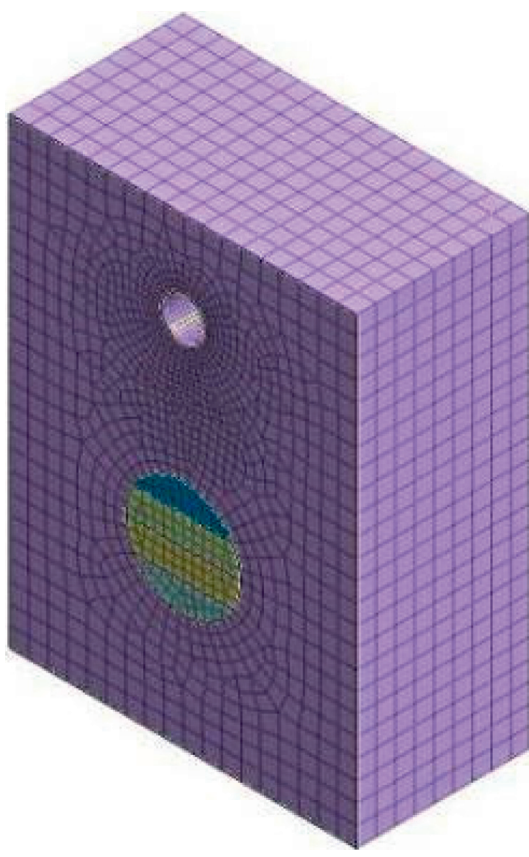

(a)

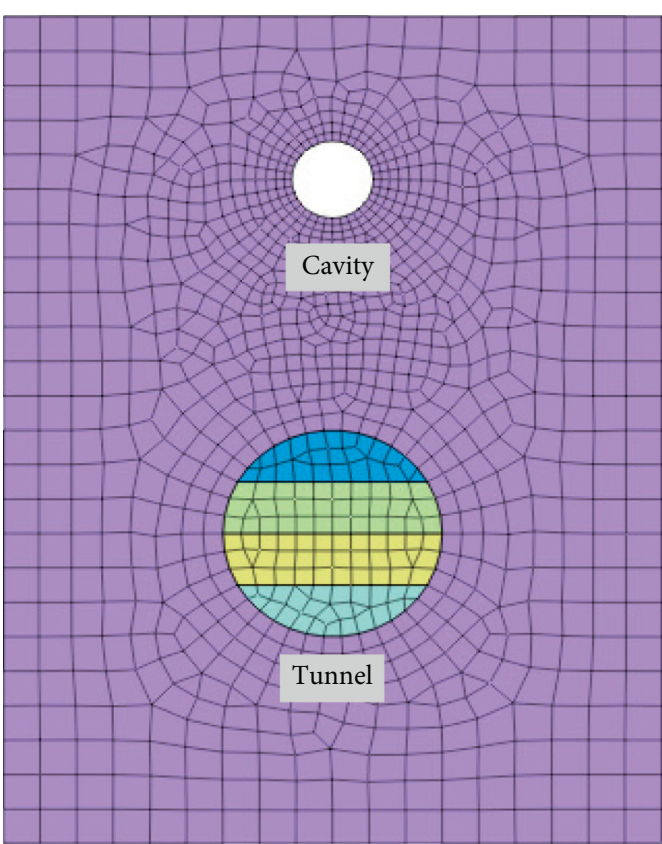

(b)

Figure 8: Tunnel excavation model with cavity. (a) Axonometric drawing. (b) Front elevation.

TABLE 3: Soil physical and mechanical parameters.

\begin{tabular}{|c|c|c|c|c|c|}
\hline Material & $\begin{array}{c}\text { Modulus of } \\
\text { elasticity } E(\mathrm{MPa})\end{array}$ & Poisson ratio $\mu$ & Unit weight $\rho_{b}\left(\mathrm{kN} \cdot \mathrm{m}^{-3}\right)$ & Cohesive strength $c(\mathrm{MPa})$ & $\begin{array}{l}\text { Internal friction } \\
\text { angle } \varphi\left({ }^{\circ}\right)\end{array}$ \\
\hline Silty clay & 15 & 0.32 & 20 & 0.041 & 19 \\
\hline
\end{tabular}

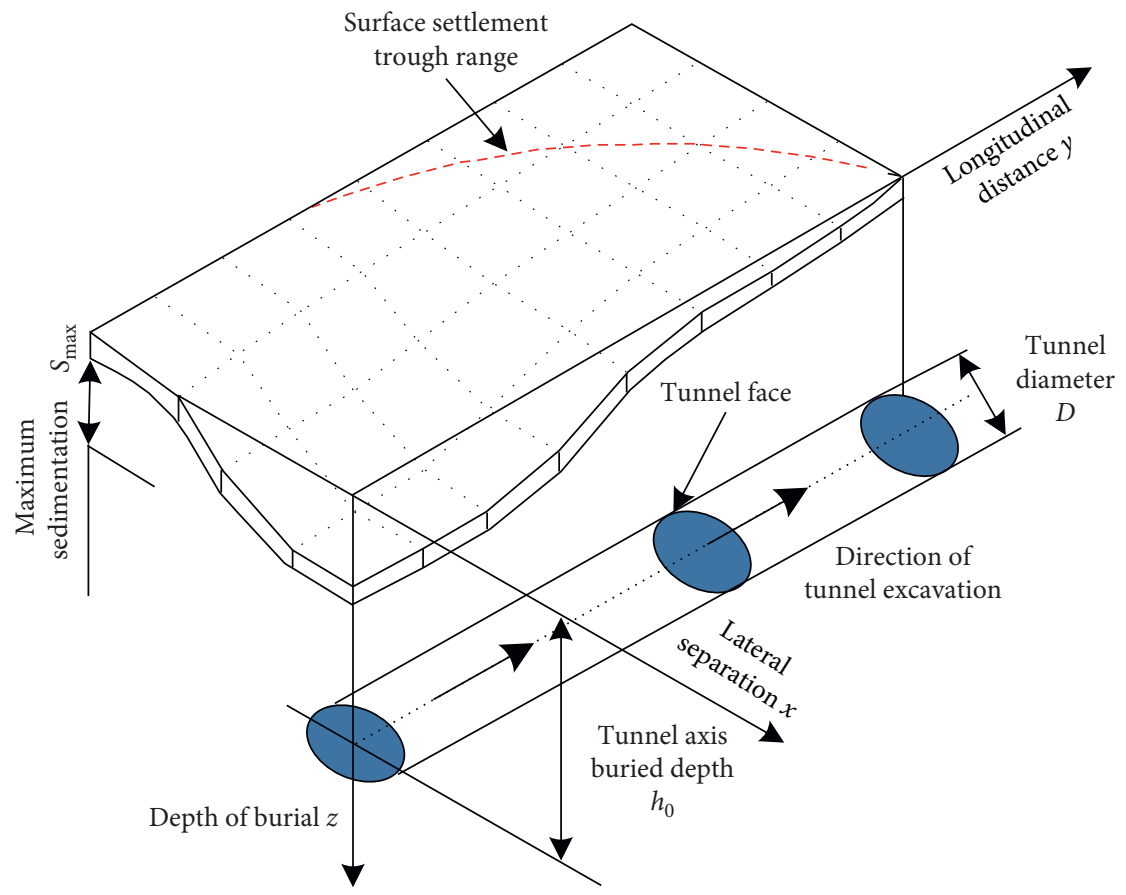

Figure 9: Three-dimensional surface sedimentation tank schematic. 


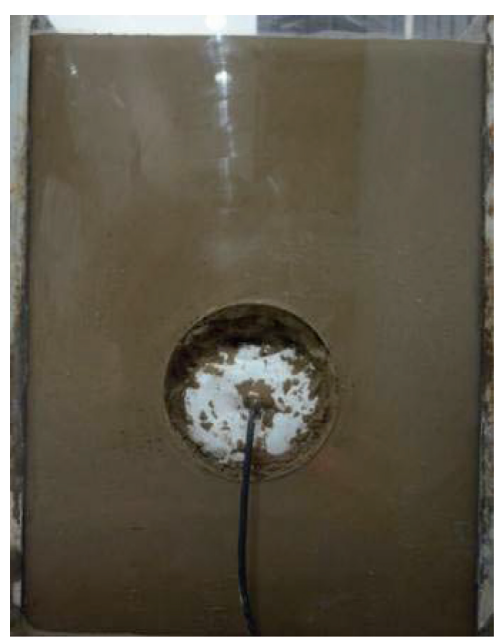

(a)

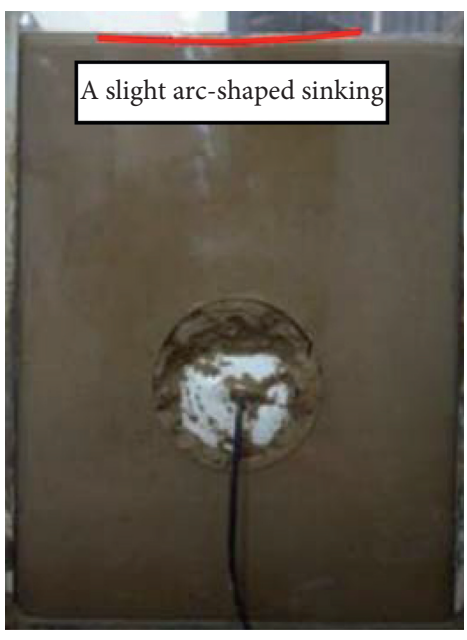

(b)

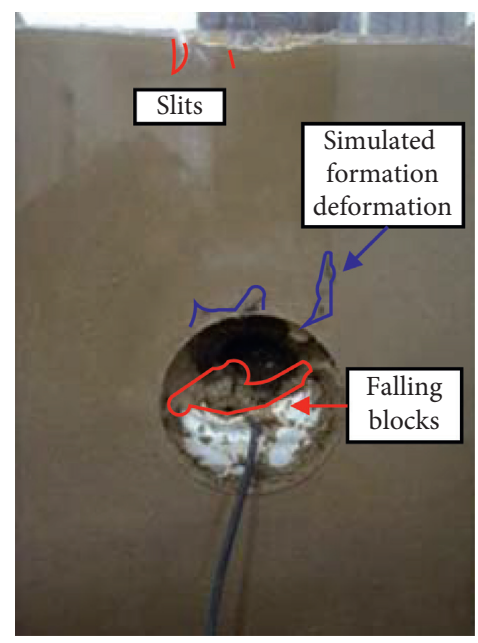

(c)

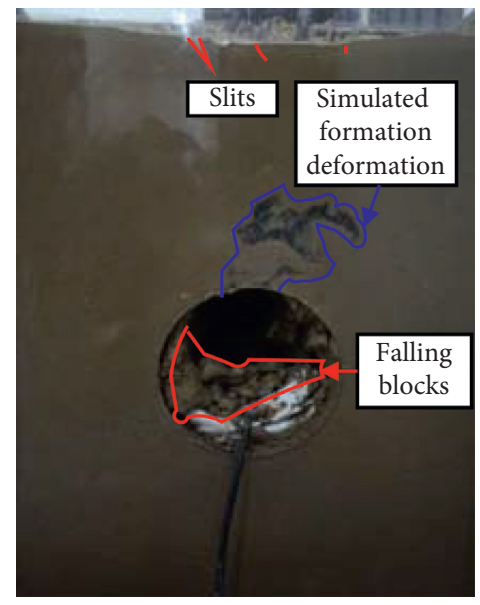

(d)

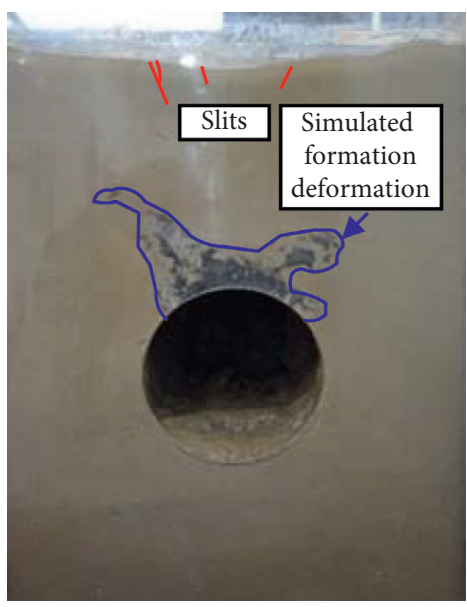

(e)

Figure 10: Instability evolution process of stratum without cavity. (a) $P=0 \mathrm{MPa}$. (b) $P=0.02 \mathrm{MPa}$. (c) $P=0.04 \mathrm{MPa}$. (d) $P=0.06 \mathrm{MPa}$. (e) $P=0.08 \mathrm{MPa}$.

empty space in the upper half, and a small collapse occurs at the upper boundary of the tunnel vault. Furthermore, the bottom boundary of the tunnel cavity slips downward, and obvious surface subsidence occurs. When $P$ is $0.06 \mathrm{MPa}$ (Figure 11(d)), the number of falling blocks in the tunnel increases, and the collapse surface of the arch roof is connected with the formation cavity slip surface. During this stage, the cavity cross section gradually changes from a regular circle to an ellipse, and the amplitude of the surface settlement trough continues to expand. Its vertical displacement is obviously greater than that in working condition 1. When $P$ is $0.08 \mathrm{MPa}$ (Figure $11(\mathrm{e})$ ), the cavity boundary is completely closed, the surface subsidence surface is finally completely connected with the tunnel arch roof collapse surface, and the entire collapse surface collapse is formed.

Figure 12 shows a complete record of the closure process of the formation cavity boundary.

In working condition 1 , the land subsidence curve is shown in Figure 13. As can be seen from the diagram, as the airbag unloading occurs in steps of $0.02 \mathrm{MPa}$, the surface subsidence trough becomes larger and more symmetrical. Maximum settlement appears directly above the tunnel. When the airbag unloading reaches $0.08 \mathrm{MPa}$, the maximum surface settlement of the no-cavity test group reaches $5.2 \mathrm{~cm}$. As the airbags were unloaded in stages, cracks appeared in the tunnel dome and eventually extended upward to form a stable arch collapse. In order to better show the entire development process of formation instability and damage caused by tunnel excavation under no-cavity conditions, the dynamic development process of instability and failure of no-cavity formation is drawn by sketch, as shown on the right side of Figure 13.

Figure 14 is the surface settlement curve of the withcavity experimental group. Table 4 provides a comparison of the maximum settlement values of the two working conditions at the same unloading level. Under the influence of the formation cavity, the surface subsidence during staged airbag unloading is larger than that in the absence of cavities and is about twice as large as that in working condition 1 . In addition, the surface settlement curve shown in Figure 14 also has a significant symmetry. The monitoring points at 


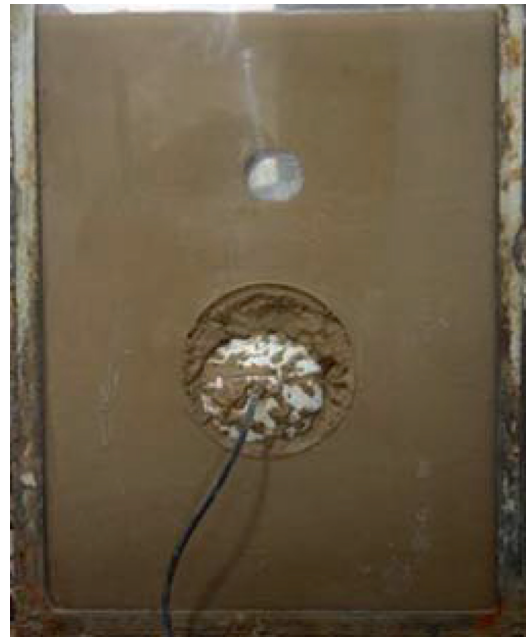

(a)

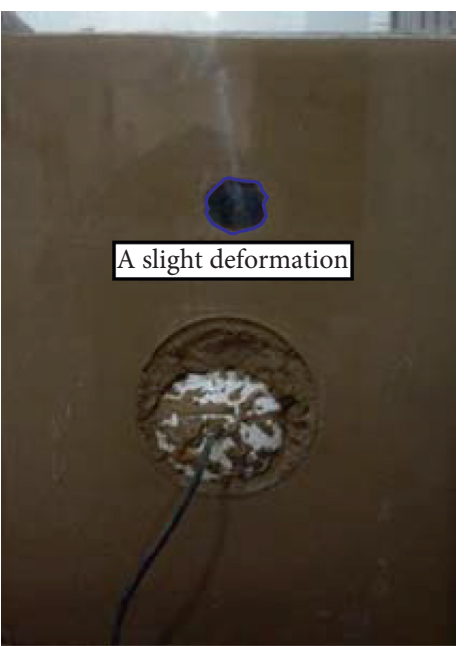

(b)

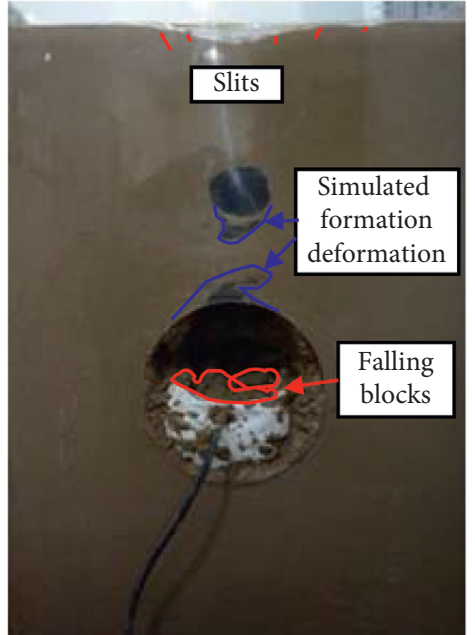

(c)

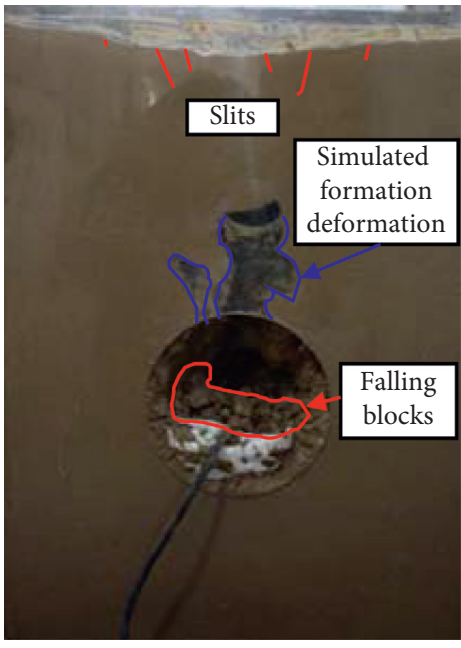

(d)

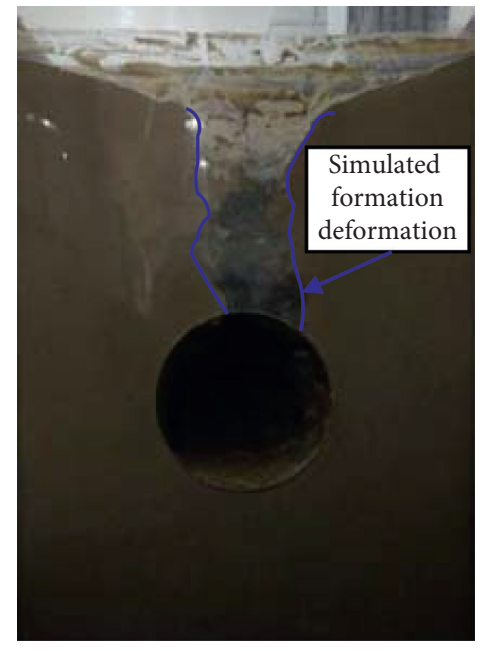

(e)

Figure 11: Instability evolution process of stratum with cavity. (a) $P=0 \mathrm{MPa}$. (b) $P=0.02 \mathrm{MPa}$. (c) $P=0.04 \mathrm{MPa}$. (d) $P=0.06 \mathrm{MPa}$. (e) $P=0.08 \mathrm{MPa}$.

$-4 \mathrm{~cm},-2 \mathrm{~cm}, 0 \mathrm{~cm}, 2 \mathrm{~cm}$, and $4 \mathrm{~cm}$ above the tunnel also show that the subsidence trend above the formation hole suddenly steepens and forms a new settlement basin. In order to better show the entire development process of formation instability and damage caused by tunnel excavation under cavity conditions, the dynamic development process of instability and failure of cavity formation is drawn by sketch, as shown on the right side of Figure 14 .

5.2. Analysis of Numerical Simulation Results. In Figure 15, the vertical displacement of the ground surface under working condition 1 is calculated by the 4 -step method in four steps (from top to bottom). It can be seen that, in the no-cavity condition, with the continuous excavation of the tunnel steps, the vertical displacement of the ground surface increases continuously, and the surface settlement of the positive roof of the tunnel is the largest. When each excavation step is applied from the top to the bottom, the increment of the surface settlement is $3.65 \mathrm{~cm}, 5.81 \mathrm{~cm}$, $6.94 \mathrm{~cm}$, and $7.58 \mathrm{~cm}$, respectively.

In Figure 16, the vertical displacement of the ground under working condition 2 is calculated using the 4-step method with 4-step excavation (from top to bottom). As can be seen from the cloud images of the excavation stage of each of the steps, when the tunnel is excavated under empty conditions, the greater the vertical settlement is, the closer it is to the arch part of the tunnel. When each excavation step is applied from top to bottom, the surface settlement values are $5.99 \mathrm{~cm}, 9.86 \mathrm{~cm}, 12.15 \mathrm{~cm}$, and $13.60 \mathrm{~cm}$, respectively. It can be seen that the existence of the formation cavity increases the magnitude of surface settlement.

Figure 17 is a graph of surface settlement values under both working conditions in the numerical simulation. It can be seen that when the step-by-step excavation of steps $1-4$ is carried out in an orderly manner, a settlement trough with the vertical center line of the tunnel as the axis of symmetry is formed. The surface settlement amplitude 


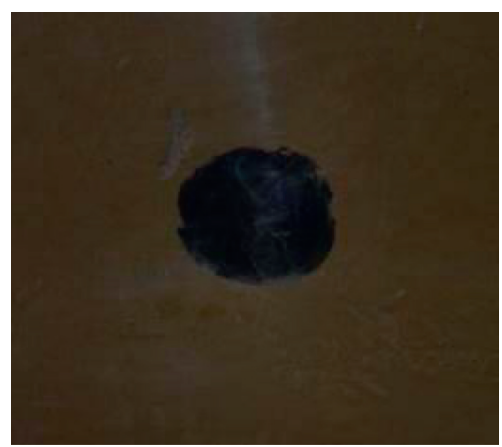

(a)

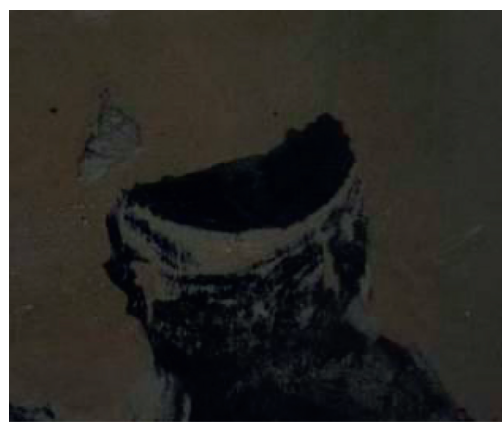

(d)

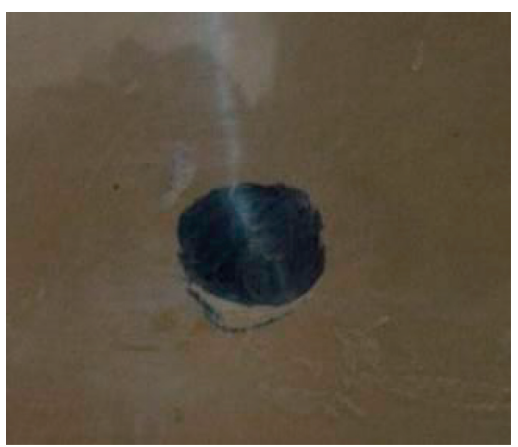

(b)

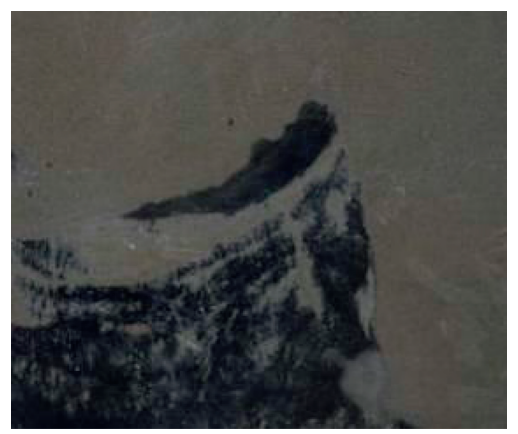

(e)

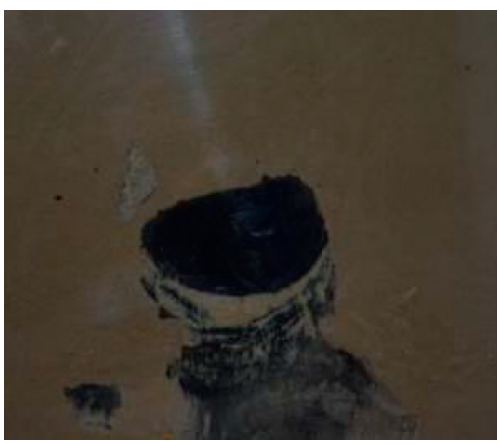

(c)

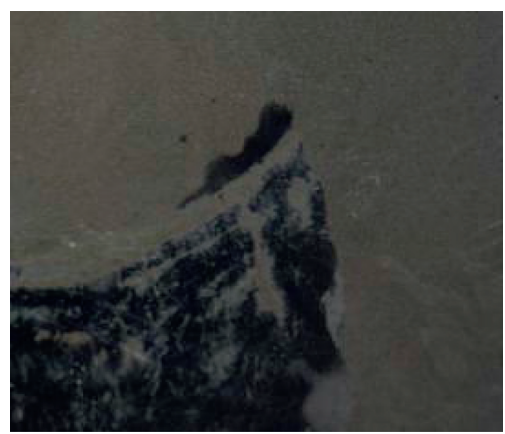

(f)

Figure 12: Stratum cavity boundary closure process. (a) Process 1. (b) Process 2. (c) Process 3. (d) Process 4. (e) Process 5. (f) Process 6.

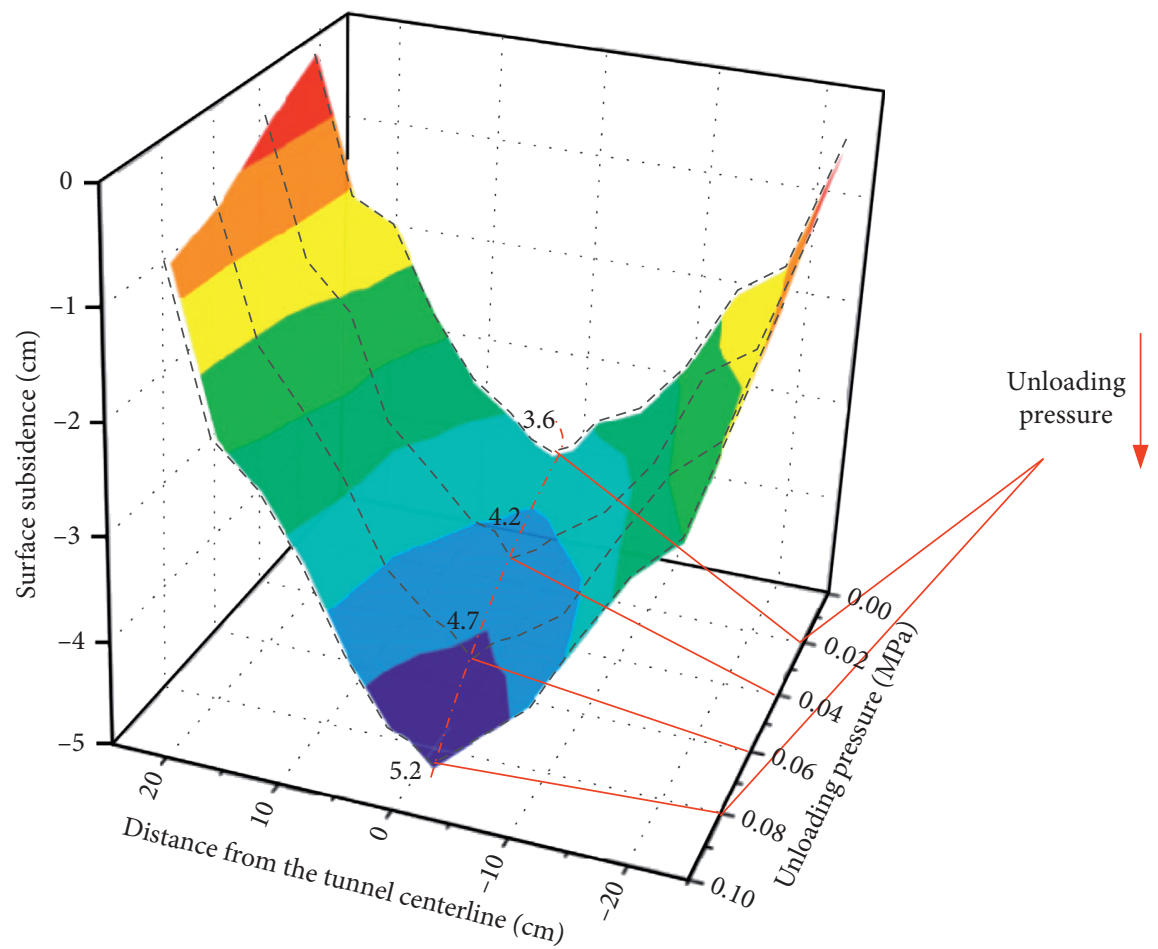

Surrounding rock failure pattern

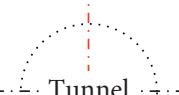

FIGURE 13: Settlement curve groove and failure pattern of surrounding rock in working condition 1. above the tunnel excavation is the largest, and the shape of the settlement groove is basically consistent under the two working conditions. The maximum settlement value of working condition 1 is $7.58 \mathrm{~cm}$, and the maximum settlement value of working condition 2 is $13.60 \mathrm{~cm}$, indicating that the existence of the cavity will aggravate the surface deformation. The result is consistent with the model test result. 


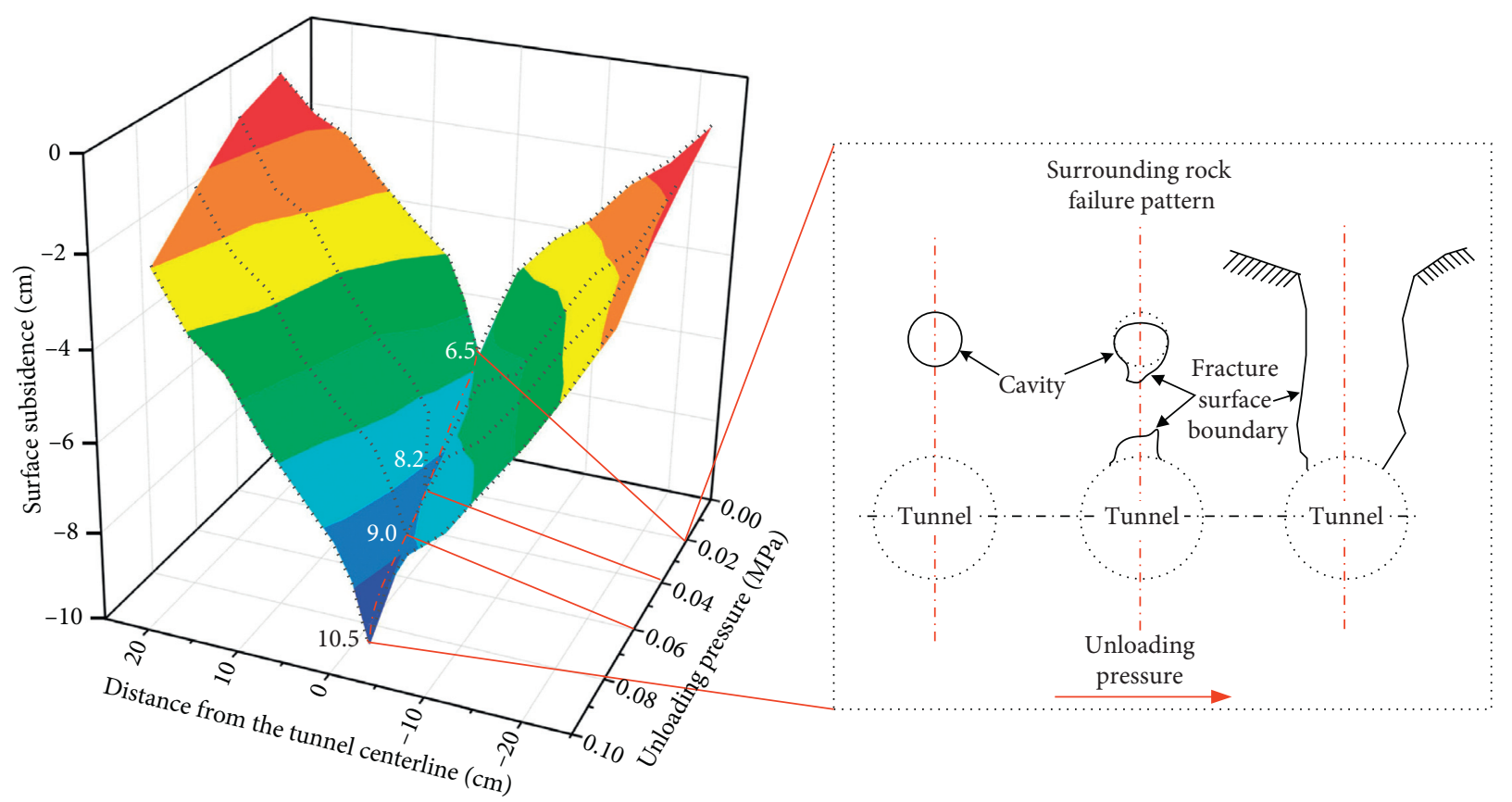

FIGURE 14: Settlement curve groove and failure pattern of surrounding rock in working condition 2.

TABLe 4: Maximum settlement value at the same unloading level $(\mathrm{cm})$.

\begin{tabular}{lcccc}
\hline \multirow{2}{*}{ Working conditions } & \multicolumn{3}{c}{ Unloading pressure $P$} \\
& 0.02 & 0.04 & 0.06 & 0.08 \\
\hline 1 & 3.6 & 4.2 & 4.7 & 5.2 \\
2 & 6.5 & 8.2 & 9.0 & 10.5 \\
\hline
\end{tabular}

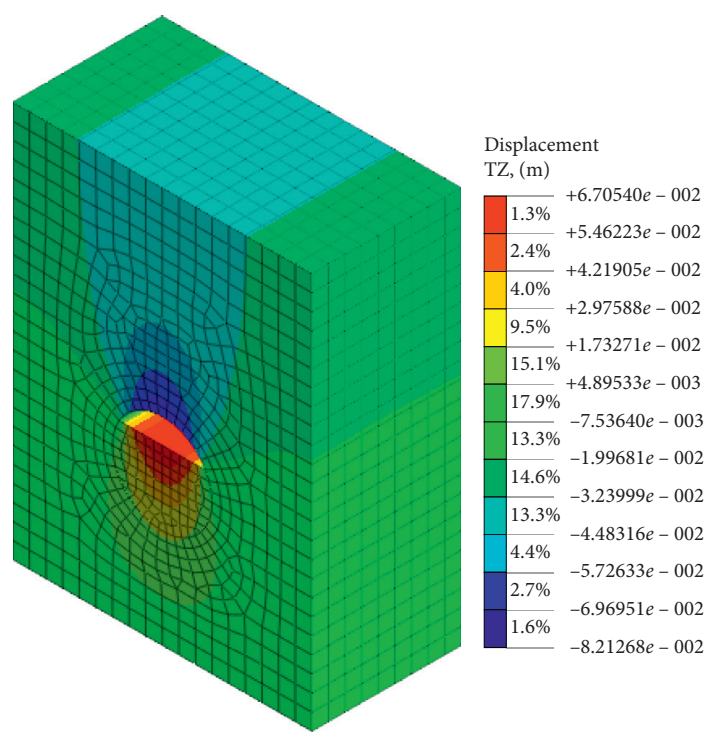

(a)

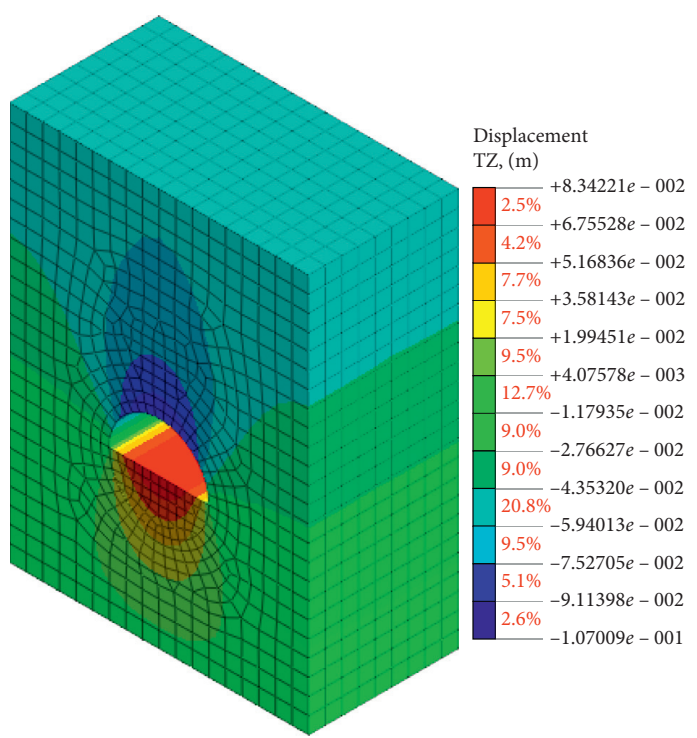

(b)

Figure 15: Continued. 


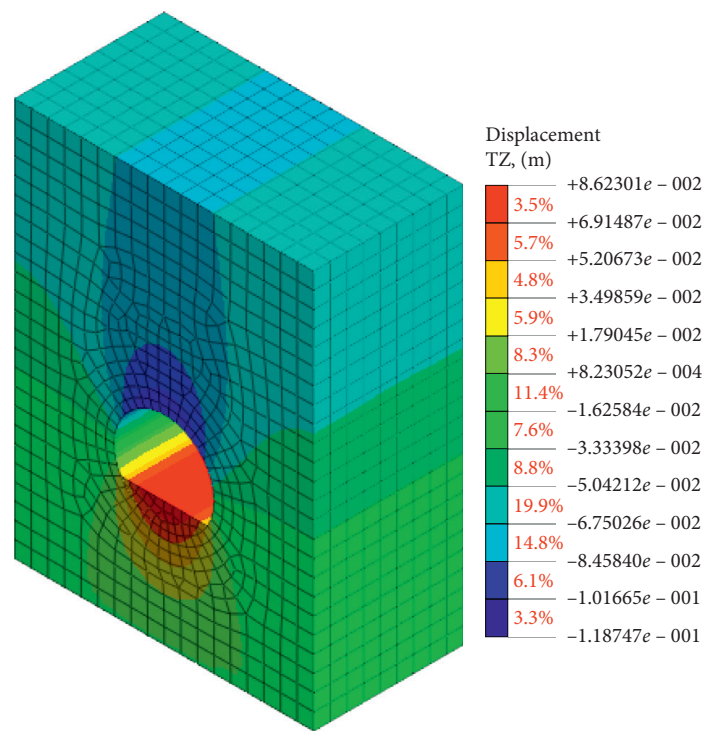

(c)

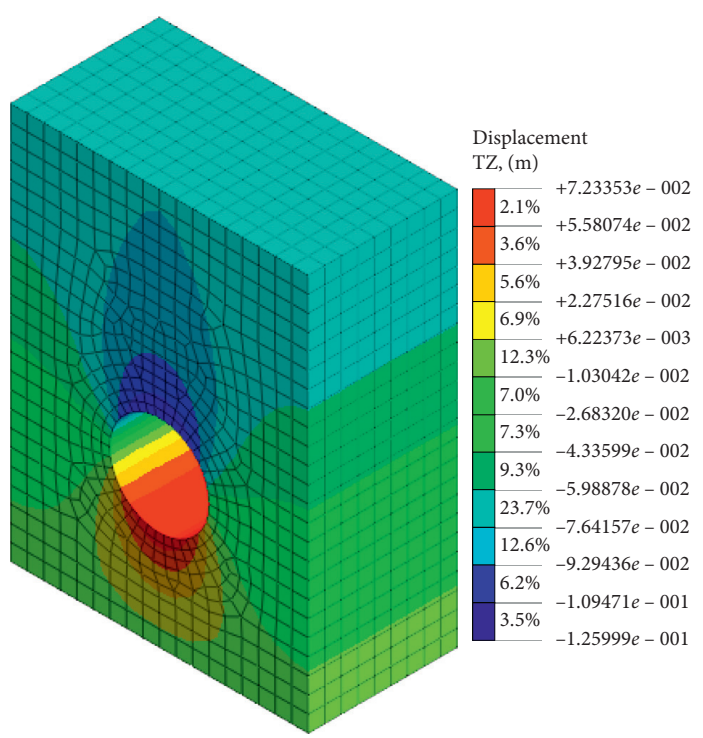

(d)

Figure 15: Vertical displacement cloud map of the ground caused by tunnel excavation without cavity. (a) Step 1. (b) Step 2. (c) Step 3. (d) Step 4.

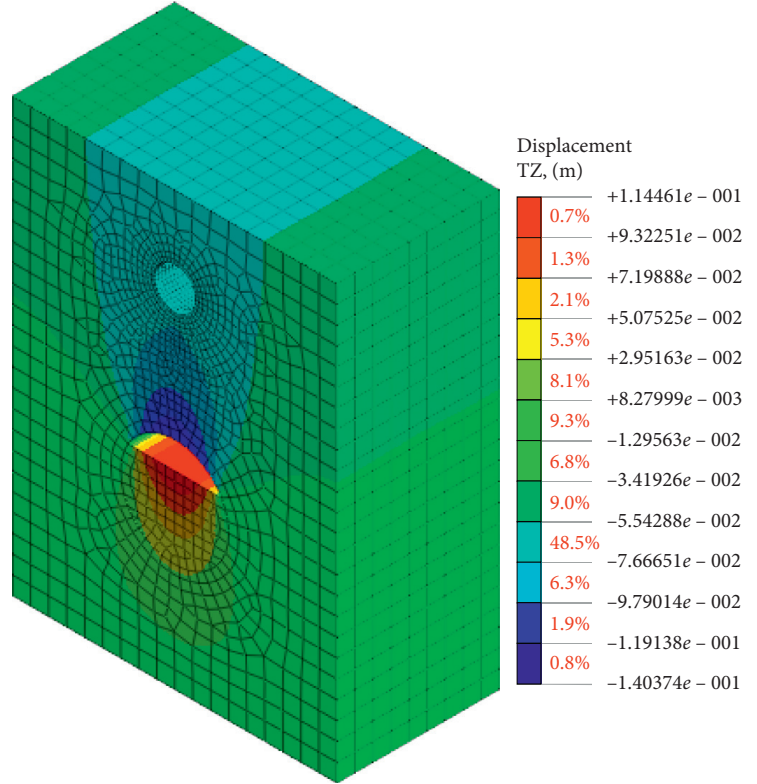

(a)

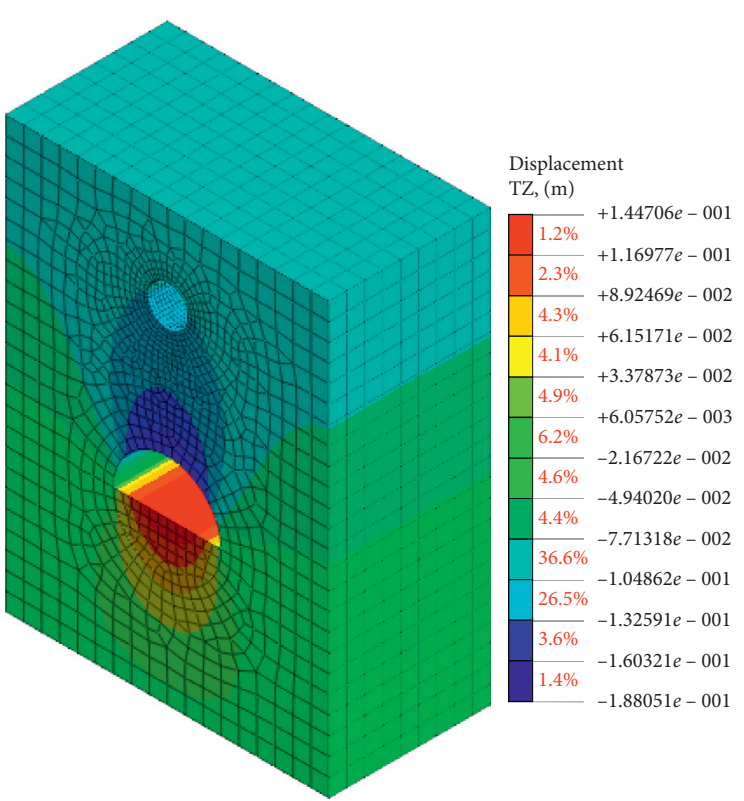

(b)

Figure 16: Continued. 


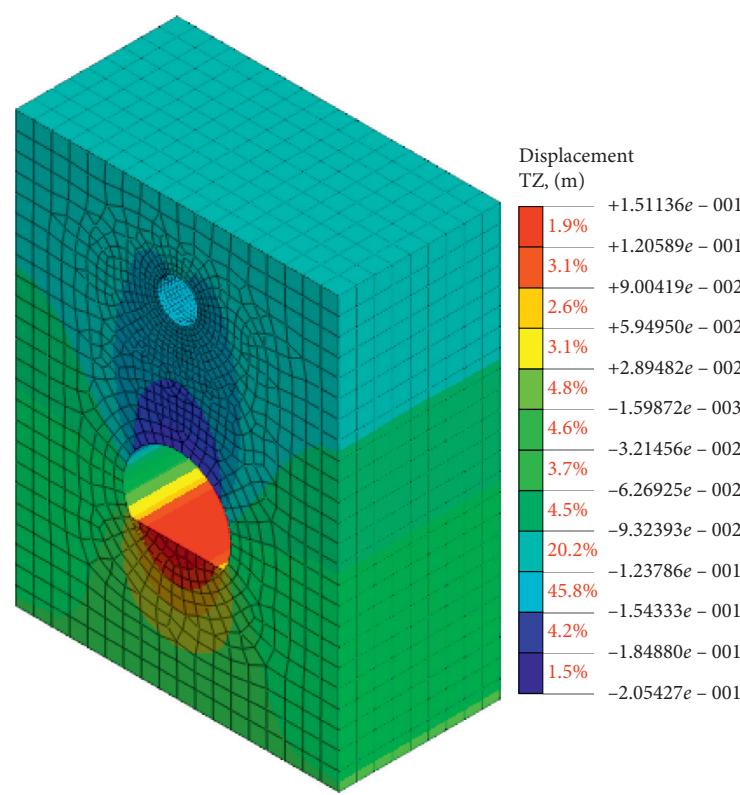

(c)

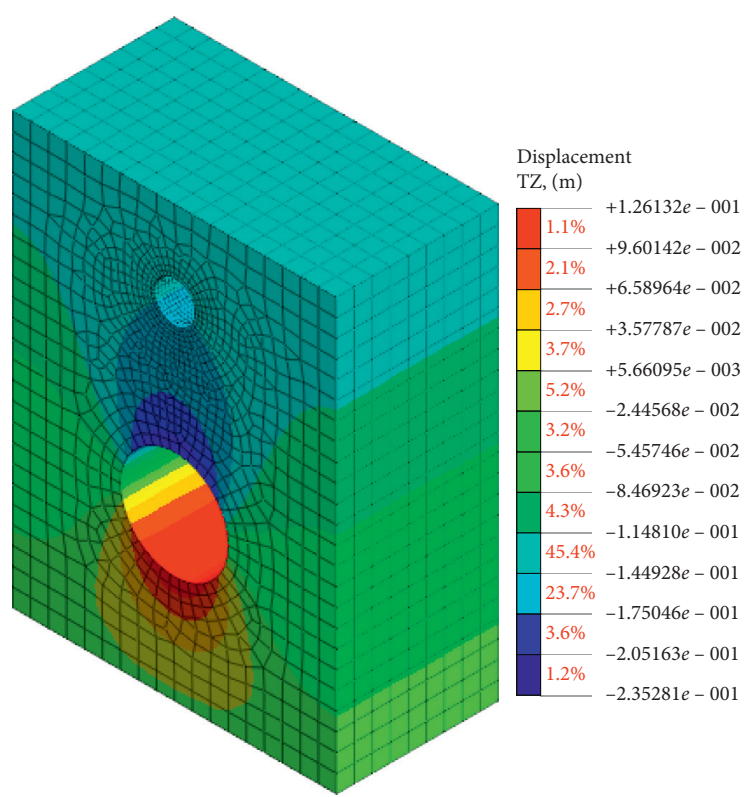

(d)

Figure 16: Vertical displacement cloud map of the ground caused by tunnel excavation with cavity. (a) Step 1. (b) Step 2. (c) Step 3. (d) Step 4.

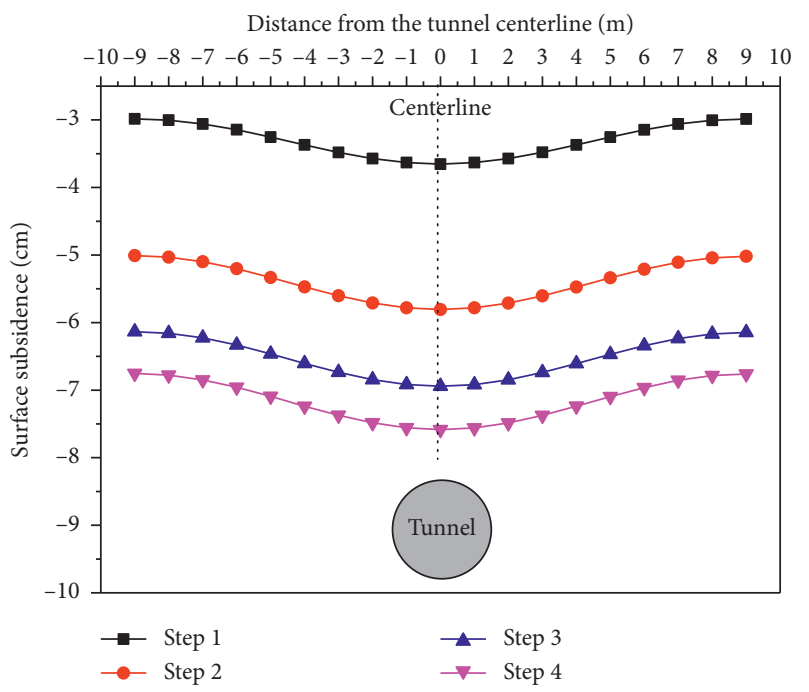

(a)

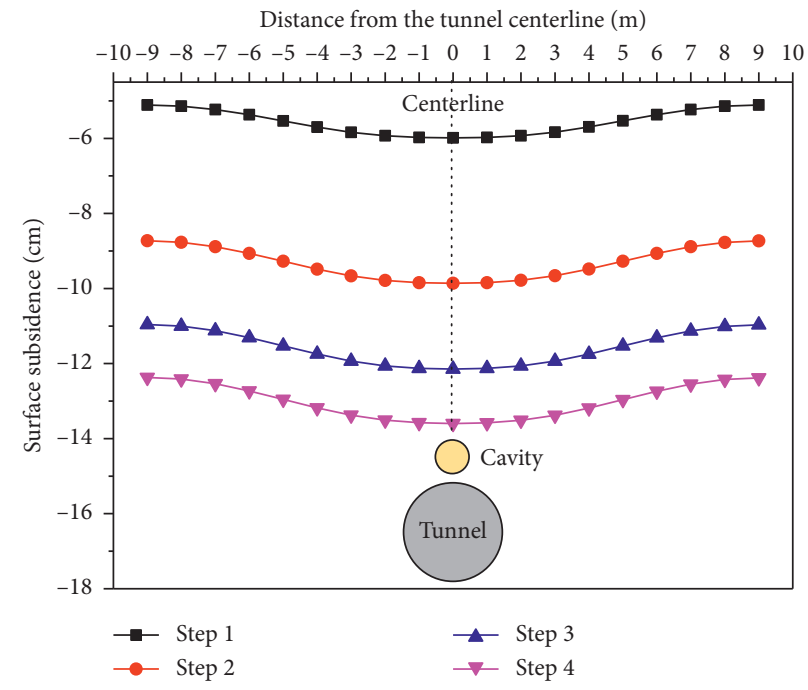

(b)

Figure 17: Surface subsidence curve of numerical simulation. (a) Without cavity. (b) With cavity.

5.3. Comparative Analysis. The comparison of model test results with and without cavity condition shows that the instability and destruction process of cavity formations are more severe than those of no-cavity formations, which may even cause collapse of the entire formation. When there is no cavity, the ground is disturbed by construction and only part of the soil at the tunnel arch cracks, and this part of the soil extends upward to a limited extent, eventually forming a stable arch collapse. When there are cavities, the instability mechanism of the stratum changes. With the gradual unloading of the airbags, the slump at the tunnel arch will expand upward and become larger, and at the same time the boundary of the stratum will slide downward and gradually close. Finally, it penetrates with the slumping surface of the tunnel arch and forms a ground collapse. The results of numerical simulation also confirm that the instability process of the stratum with cavity is more severe than that of the stratum without cavity.

The maximum surface settlement under different excavation stages without cavity is compared and analyzed (Figure 18). It can be seen that under the same step sequence, the maximum surface settlement values obtained from the 


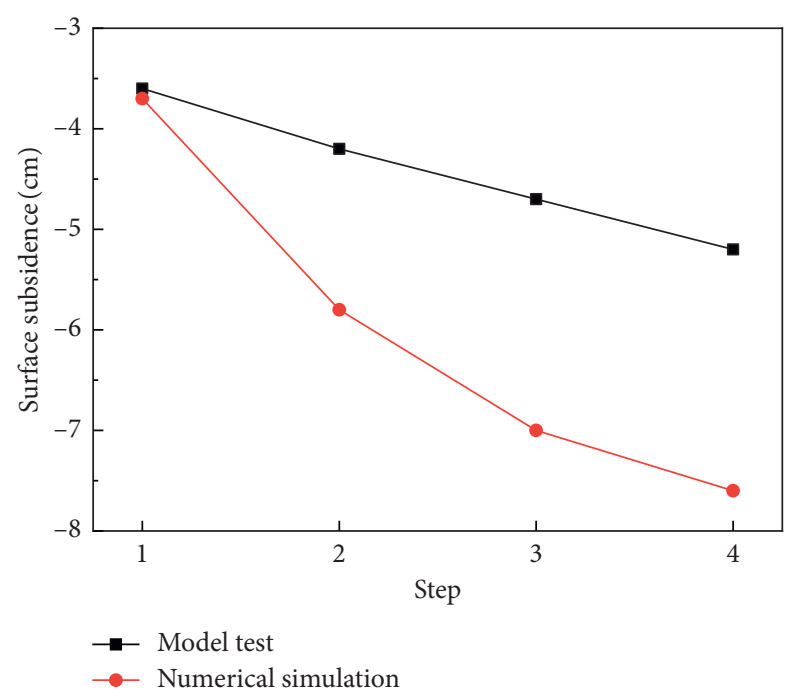

Figure 18: Comparison of maximum surface subsidence in working condition 1.

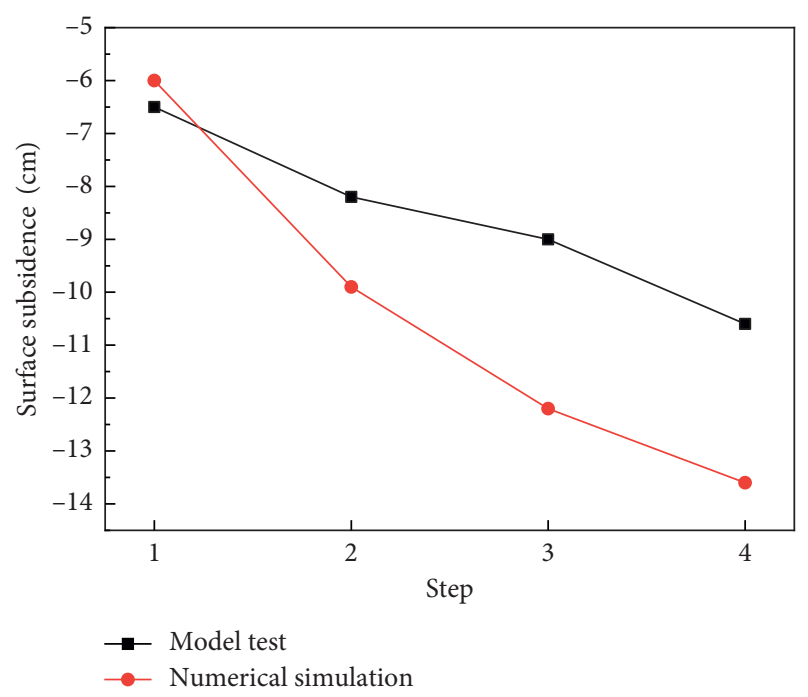

Figure 19: Comparison of maximum surface subsidence in working condition 2.

numerical simulation results are larger than the model test values. With the exception of the results of step 1 , the maximum ground subsidence values obtained in steps $2-4$ of the numerical simulation were 1.38 times, 1.47 times, and 1.46 times those of the model test, respectively. Figure 19 presents a comparison of the maximum surface settlement in different excavation stages with a cavity (Figure 18). It can be seen that, in the same step, in addition to the results obtained in step 1, the maximum surface settlement values of steps $2-4$ of the numerical simulation results are 1.20 times, 1.35 , and 1.30 times those of the model test, respectively. Although the numerical simulation and model test have obvious gaps in the numerical values, the growth laws of the two methods are the same, which indicates that the formation instability laws obtained by the two research methods are the same. The existence of hollow structures will aggravate the degree of formation instability during tunnel excavation. The reasons for the large differences between model tests and numerical simulations are as follows: (1) Model test similarity ratio: the numerical simulation is based on the original size, and the model test uses a geometric similarity ratio of $1 / 30$ and a physical mechanical parameter similarity ratio of 1. (2) Soil properties: according to previous studies [22-24], differences in soil properties may have large experimental deviations. (3) Boundary conditions: numerical simulations simplify field boundary conditions, while model tests are constrained according to plane strain conditions.

\section{Conclusion}

In this paper, through the self-designed plane strain model test, the instability process of cavity-containing strata under the disturbance of subway tunnel construction is directly observed. The instability mechanism of cavity-bearing strata under the disturbance of subway tunnel construction is studied and compared with the numerical simulation results. The following conclusions can be drawn:

(1) Compared with a no-cavity stratum, the destruction process of the a stratum with a cavity under disturbance due to shallow tunnel construction is more rapid, the degree of damage is more severe, the development and evolution law of formation fracture is more complex, and the scope of ground collapse is wider. Therefore, effective measures should be taken to prevent and control accidents caused by the unstable failure of formation cavities during the construction of shallow tunnels adjacent to formation cavities.

(2) In cavity-bearing strata, with the excavation of the tunnel, the arched collapse surface at the arch top of the tunnel will expand upward and become progressively larger. At the same time, the boundary of the formation cavity will slip down and close down gradually, eventually connecting with the collapse surface of the tunnel arch. Under the influence of the formation cavity, the ground subsidence increases sharply. In addition, the subsidence trend above the cavity will suddenly become steeper and form a new subsidence basin. The unstable failure process of the cavity formation will be more severe than that of the no-cavity formation, which will eventually lead to collapse failure of the whole formation.

(3) Due to the large gap between the model test and numerical simulation results in this study, this paper only qualitatively proposes the instability mechanism of the stratum containing cavities under the disturbance of subway tunnel construction. The reasons for the large gap between the two test results are as follows: (1) similarity ratio of model tests; (2) soil layer properties; (3) boundary conditions. We will analyze this further in the future.

\section{Data Availability}

The data used to support the findings of this study are included within the article. 


\section{Conflicts of Interest}

The authors declare that there are no conflicts of interest regarding the publication of this paper.

\section{Acknowledgments}

The study was supported by the Fundamental Research Funds for the Central Universities (nos. 201962011 and 201961037) and the National Natural Science Foundation of China (nos. 41672272, 41427803, and 41602318).

\section{References}

[1] C. E. Augarde, A. V. Lyamin, and S. W. Sloan, "Prediction of undrained sinkhole collapse," Journal of Geotechnical and Geoenvironmental Engineering, vol. 129, no. 3, pp. 197-205, 2003.

[2] G. Idinger, P. Aklik, W. Wu, and R. I. Borja, "Centrifuge model test on the face stability of shallow tunnel," Acta Geotechnica, vol. 6, no. 2, pp. 105-117, 2011.

[3] Y. Hong, C. W. W. Ng, G. B. Liu, and T. Liu, "Three-dimensional deformation behaviour of a multi-propped excavation at a "greenfield" site at Shanghai soft clay," Tunnelling and Underground Space Technology, vol. 45, pp. 249-259, 2015.

[4] L.-J. Tao, S. Yuan, and J.-H. An, "Development mechanism of cavity damage under urban roads and its influence on road surface subsidence," Journal of Heilongjiang University of Science \& Technology, vol. 25, no. 3, pp. 289-293, 2015, in Chinese.

[5] B. Liu, W.-J. Dai, W. Peng, and X.-L. Meng, "Spatio-temporal analysis of the land subsidence in the UK using independent component analysis," in Proceedings of 2014 3rd International Workshop on Earth Observation and Remote Sensing Applications, pp. 294-298, Changsha, China, June 2014.

[6] H.-H. Liu, Y.-Q. Zhang, and R. Wang, "The reason of land subsidence and prevention measures of Beijing segment of Beijing-Tianjin high-speed rail," in Proceedings of 2014 3rd International Workshop on Earth Observation and Remote Sensing Applications, pp. 323-325, Changsha, China, June 2014.

[7] K.-I. Song, G.-C. Cho, and S.-B. Chang, "Identification, remediation, and analysis of karst sinkholes in the longest railroad tunnel in South Korea," Engineering Geology, vol. 135-136, pp. 92-105, 2012.

[8] T. Li, Z.-Z. Zhang, and L.-D. Zong, "Study on formation mechanism and prediction of soil subsidence caused by underground cavity," Geotechnical Mechanics, vol. 36, no. 7, pp. 1995-2002, 2015, in Chinese.

[9] A.-Z. Lu, X.-T. Zeng, and Z. Xu, "Solution for a circular cavity in an elastic half plane under gravity and arbitrary lateral stress," International Journal of Rock Mechanics and Mining Sciences, vol. 89, pp. 34-42, 2015.

[10] H.-C. Wang, "Analysis and evaluation of the influence of shallow excavation tunnel adjacent to stratum cavity construction," Master's thesis, Beijing Jiaotong University, Beijing, China, 2018.

[11] M. Tao, H. Zhao, X. Li, X. Li, and K. Du, "Failure characteristics and stress distribution of pre-stressed rock specimen with circular cavity subjected to dynamic loading," Tunnelling and Underground Space Technology, vol. 81, pp. 1-15, 2018.
[12] W. A. Abdulla and D. J. Goodings, "Modeling of sinkholes in weakly cemented sand," Journal of Geotechnical Engineering, vol. 122, no. 12, pp. 998-1005, 1996.

[13] Z.-H. Ouyang, "The role of potential soil cavity on ground subsidence and collapse in coal mining area," Journal of Coal Science and Engineering (China), vol. 16, no. 3, pp. 240-245, 2010.

[14] Y. H. Hatzor, I. Wainshtein, and D. Bakun Mazor, "Stability of shallow karstic caverns in blocky rock masses," International Journal of Rock Mechanics and Mining Sciences, vol. 47, no. 8, pp. 1289-1303, 2010.

[15] GB 50021-1994, Code for Investigation of Geotechnical Engineering, China Communication Press, Beijing, China, 1994.

[16] Z. Chen, J. Liu, Z. Pan, L. D. Connell, and D. Elsworth, "Influence of the effective stress coefficient and sorption-induced strain on the evolution of coal permeability: model development and analysis," International Journal of Greenhouse Gas Control, vol. 8, pp. 101-110, 2012.

[17] K. A. Tariq and T. Maki, "Mechanical behaviour of cementtreated sand," Construction and Building Materials, vol. 58, pp. 54-63, 2014.

[18] W. Cheng, L. Sun, G. Wang, W. Du, and H. Qu, "Experimental research on coal seam similar material proportion and its application," International Journal of Mining Science and Technology, vol. 26, no. 5, pp. 913-918, 2016.

[19] Z.-J. Ma, "Study on the absorb characteristic of vibration energy and properties modification for the silty in Yellow river estuary," Master's thesis, Ocean University of China, Qingdao, China, 2007.

[20] C.-P. Zhang, X. Zhang, and H. Li, "Model tests on failure laws of ground with voids induced by shallow tunnelling," Chinese Journal of Geotechnical Engineering, vol. 38, no. 2, pp. 263270, 2016, in Chinese.

[21] Q.-Q. Li, F. Yin, and D.-L. Zhang, "Stability of a hollow cavity with complex displacement boundary conditions," Modern Tunneling Technology, vol. 55, no. 4, pp. 87-96, 2018, in Chinese.

[22] T. Liu, W. Sun, H. Kou et al., "Experimental study of leakage monitoring of diaphragm walls based on distributed optical fiber temperature measurement technology," Sensors, vol. 19, no. 10, p. 2269, 2019.

[23] W.-C. Cheng, J. C. Ni, A. Arulrajah, and H.-W. Huang, "A simple approach for characterising tunnel bore conditions based upon pipe-jacking data," Tunnelling and Underground Space Technology, vol. 71, pp. 494-504, 2018.

[24] W.-C. Cheng, L. Wang, Z.-F. Xue, J. C. Ni, M. M. Rahman, and A. Arulrajah, "Lubrication performance of pipejacking in soft alluvial deposits," Tunnelling and Underground Space Technology, vol. 91, Article ID 102991, 2019. 